\title{
Natural Killer Cell IFN $\gamma$ Secretion is Profoundly Suppressed Following Colorectal Cancer Surgery
}

\author{
Leonard Angka, MSc ${ }^{1,2}$, Andre B. Martel, MD ${ }^{1,3}$, Marisa Kilgour, BSc ${ }^{4}$, Ahwon Jeong, BSc ${ }^{1}$, Manahil Sadiq, BSc ${ }^{1}$, \\ Christiano Tanese de Souza, DVet ${ }^{1}$, Laura Baker, MD $^{1,3}$, Michael A. Kennedy, PhD $^{1}$, Natasha Kekre, MD, \\ $\mathrm{MPH}^{1,2,5}$, and Rebecca C. Auer, MD, MSc ${ }^{1,2,3}$ \\ ${ }^{1}$ Centre for Innovative Cancer Research, Ottawa Hospital Research Institute, Ottawa, ON, Canada; ${ }^{2}$ Department of \\ Microbiology and Immunology, University of Ottawa, Ottawa, ON, Canada; ${ }^{3}$ Division of General Surgery, Department of \\ Surgery, University of Ottawa, Ottawa, ON, Canada; ${ }^{4}$ Deely Research Centre, BC Cancer Agency, Victoria, BC, Canada; \\ ${ }^{5}$ Blood and Marrow Transplant Program, The Ottawa Hospital, Ottawa, ON, Canada
}

\begin{abstract}
Background. Surgical stress results in a significant reduction in natural killer (NK) cell cytotoxicity (NKC), which has been linked to postoperative cancer metastases. However, few studies have measured the impact of surgical stress upon NK cell IFN $\gamma$ secretion (NKA), a cytokine with essential roles in controlling infection and metastases. The objective of this study was to investigate the impact of surgical stress on NKA in colorectal cancer (CRC) surgery patients.

Methods. Peripheral blood was collected from CRC surgery patients $(n=42)$ preoperatively and on postoperative day (POD) 1, 3, 5, 28, and 56. Healthy donor blood $(n=27)$ was collected for controls. We assessed NKA by production of IFN $\gamma$ following whole blood cytokine stimulation, NKC by ${ }^{51} \mathrm{Cr}$-release assay, and immune cell profiling by flow cytometry.

Results. The mean reduction in NKA on POD1 compared with baseline was $83.1 \%$ (standard deviation $25.2 \%$; confidence interval 75-91), and therefore the study met the primary endpoint of demonstrating a $>75 \%$ decrease in a cohort of CRC surgery patients $(p<0.0001)$. The
\end{abstract}

Electronic supplementary material The online version of this article (https://doi.org/10.1245/s10434-018-6691-3) contains supplementary material, which is available to authorized users.

(C) The Author(s) 2018

First Received: 25 January 2018;

Published Online: 5 September 2018

R. C. Auer, MD, MSc

e-mail: rauer@toh.ca profound and universal suppression of NKA persisted with $65.5 \%(19 / 29)$ and $33.3 \%$ (4/12) of patients with levels measuring $<75 \%$ of baseline on POD28 and POD56 respectively. The NKC was significantly reduced on POD1, but the degree was less pronounced $(24.6 \%, p=0.0024)$. Immune cell profiling did not reveal differences in the absolute number of NK cells $\left(\mathrm{CD}^{-}{ }^{-} \mathrm{CD} 56^{+}\right)$or the ratio of CD56 $6^{\text {dim }}$-to-CD56 $6^{\text {bright }}$ subsets.

Conclusions. NKA is significantly suppressed for up to two months following surgery in CRC patients, a degree of surgery-induced immunosuppression far worse than previously reported.

Natural killer (NK) cells are cytotoxic lymphocytes of the innate immune system. Immunosurveillance of malignant and infected cells by NK cells results in direct cytotoxicity and the production of immune stimulating cytokines. NK cells play a central role in the control of cancer metastases. ${ }^{1}$ Clinical studies have linked intratumoral NK cell infiltration, as well as peripheral blood NK cell effector functions with cancer prognosis and incidence. $^{2-7}$ Transient impairment in NK cell cytotoxicity (NKC) following surgery has been linked to cancer recurrence and metastases in both animal models and human studies. ${ }^{8-13}$ Several clinical studies have been designed to attenuate the detrimental effects of surgical stress on NK cells with the goal of improving prognosis. ${ }^{11-16}$

Beyond NKC, cytokine secretion represents an additional NK cell effector function critically involved in the antitumour immune response. The two main subsets of human NK cells can be distinguished based on expression 
of CD56 and CD16. While cytotoxic activity in the resting state is primarily assigned to $\mathrm{CD} 56^{\mathrm{dim}} / \mathrm{CD} 16^{+} \mathrm{NK}$ cells, the stimulated production of cytokines, in particular interferon-gamma (IFN $\gamma$ ), is attributed to both the CD56 $6^{\mathrm{dim}}$ / $\mathrm{CD} 16^{+}$and $\mathrm{CD} 56^{\text {bright }} / \mathrm{CD} 16^{-}$populations. ${ }^{17}$ Moreover, $\mathrm{NK}$-secreted IFN $\gamma$ is responsible for shaping the adaptive immune response, and correlated with tumour stage and cancer prognosis. ${ }^{5,18-21}$ This suggests that measurement of IFN $\gamma$ may provide a more comprehensive overview of $\mathrm{NK}$ cell activity (NKA). ${ }^{22}$

The present study is the first to investigate the effects of major surgery on NK cell IFN $\gamma$ secretion (or "NKA") in cancer patients. To measure NKA, we used an assay, which has been shown specifically to stimulate NK cell-IFN $\gamma$ production from whole blood. ${ }^{19}$ We report that NKA is universally and profoundly suppressed in the postoperative period, with a greater magnitude and duration compared with NKC. This alternative assay of NK cell dysfunction has important implications for understanding how the immunosuppressive effects of surgery impact the development of subsequent metastases, which will aid in the design of perioperative immunotherapies.

\section{METHODS}

\section{Patient Characteristics and Clinical Protocol}

This single center, prospective, translational study, approved by the Ottawa Health Science Research Ethics Board (20160012-01H), was conducted between August 2016 and June 2017. Eligible patients were $>40$ years of age and had a histologically confirmed diagnosis of primary colorectal cancer and a planned surgical resection of the primary tumour (CRC cohort) or healthy donors who volunteered to participate (HD cohort). Exclusion criteria included a history of active viral or bacterial infection or known HIV or Hepatitis B or C, autoimmune diseases, use of immunosuppressive medications, or prior anticancer treatments. All subjects provided written, informed consent.

The primary objective was to compare the reduction in NKA on postoperative day (POD) 1 compared with preoperative (baseline) in the CRC cohort. The secondary objective was to compare NKA at baseline in the CRC cohort to the HD cohort. Exploratory studies included measurement of NKA secretion on POD3, POD5 (optional and only if patient still hospitalized), POD28, and POD56, comparing NKA and NKC across different CRC AJCC cancer stages.

\section{Blood Processing}

Patient and HD blood was drawn into BD Vacutainer Sodium-Heparin coated tubes ( $\sim 20 \mathrm{~mL} /$ blood draw). One milliliter of whole blood was aliquoted into vacutainer tubes containing Promoca ${ }^{\mathrm{TM}}$ and from the remaining whole blood sample peripheral blood mononuclear cells (PBMCs) were isolated by Ficoll density centrifugation before cryopreservation.

\section{Immune Monitoring}

NKA Assay NK-secreted IFN $\gamma$ levels were measured by ELISA following stimulation of $1 \mathrm{ml}$ of whole blood, as described by the manufacturer (ATGen, NK-Vue ${ }^{\mathrm{TM}}$ ) and in prior publications, with the exception that blood was not drawn directly into tubes containing the proprietary stimulating cytokine cocktail (Promoca ${ }^{\mathrm{TM}}$ ). ${ }^{23}$ This may result in slight differences in absolute NKA compared with prior studies (ATGen, NK-Vue ${ }^{\mathrm{TM}}$ ). All plasma samples were stored at $-80^{\circ} \mathrm{C}$. The upper and lower limits of detection of the assay were $4000 \mathrm{pg} / \mathrm{mL}$ and $15.6 \mathrm{pg} / \mathrm{mL}$ respectively, and values exceeding these were assigned the cutoff values.

NKC Assay Cytotoxicity was measured using the ${ }^{51} \mathrm{Cr}$ release assay as previously described. ${ }^{8}$ Briefly, K562 target cells were labelled with ${ }^{51} \mathrm{Cr}$ before co-incubation with PBMCs at increasing concentrations (PBMC:Targets $=10: 1$, 50:1, and 100:1) in triplicate from cryopreserved samples. Following incubation, supernatants were collected and ${ }^{51} \mathrm{Cr}$ was determined by a gamma counter.

NK Cell Immunophenotyping Cryopreserved PBMCs $\left(10^{6}\right)$ were thawed and stained with BV510 Fixable viability dye, CD3, CD56, CD16, and CD14 in Brilliant Stain Buffer (BD). Samples were run on the BD FACSCelesta and analysed with FlowJo v10.

\section{Statistical Analysis}

The primary endpoint was to determine if NKA is significantly decreased on POD1 compared with baseline in the CRC surgery cohort. The secondary endpoint was to determine if there is a significant reduction in NKA in the baseline CRC patients compared with HD. Based on our previous studies of postoperative suppression of NKC, we anticipated $>75 \%$ reduction in NKA from baseline. ${ }^{24}$ Given the expected mean for CRC patients (mean $=263.6$, standard deviation $[\mathrm{SD}]=349)$, we have an $80 \%$ power to detect this difference using a two-sided paired Wilcoxon rank-sum test $(\alpha=0.05)$ with a sample size of $40 \mathrm{CRC}$ 
patients (measured at baseline and POD1). ${ }^{19}$ For the secondary endpoint, we have $>90 \%$ power to detect a difference between the CRC patient cohort (baseline) and the HD cohort using a two-sided Mann-Whitney test $(\alpha=0.05)$, with a sample size of 20 HD. Demographic data was summarized using the median values and $95 \%$ confidence interval (CI). Unpaired, nonparametric MannWhitney $U$ tests were performed when comparing two groups and paired Wilcoxon rank-sum was used to compare two paired samples (i.e., different timepoints or different assays at a single timepoint). Multiple comparisons were tested with nonparametric Kruskal-Wallis tests. $P$ values $<0.05$ were considered significant.

\section{RESULTS}

\section{Demographic Data}

The demographic data for $27 \mathrm{HD}$ and 42 CRC surgery patients is a summarized in Table 1 . There was no significant difference in the median age between the HD and CRC groups. A similar number of patients undergoing open $(n=20)$ or laparoscopic $(n=22)$ surgery were included, with an even distribution between Stage I, II, and III patients (33.3, 26.2, and $28.6 \%$ respectively). Five (11.9\%) patients were Stage IV undergoing combined resection of primary and metastatic tumours.

Scheduled preoperative and postoperative blood draws were collected when possible. The optional POD5 blood draw was collected for only 12 due to earlier discharge. The POD56 collection was added as an amendment following initial results, demonstrating a persistent decrease in NKA at POD28, resulting in a sample size of 12 .

\section{NKA is Decreased in CRC Patients}

In agreement with previously reported findings, CRC patients had a significantly lower NKA (median: $299.5 \mathrm{pg} /$ mL; CI: 159-391) compared with HD (median: $966 \mathrm{pg} / \mathrm{mL}$; CI: $398-2027 ; p=0.0006$; Fig. 1$).{ }^{19}$ Notably, NKA was decreased with advancing age and was significantly reduced in patients $>70$ years old (median: 111 pg/mL, CI: 39-629) compared with patients $<60$ years old (median: $391 \mathrm{pg} /$ mL, CI: 337-2575; $p=0.04$; Supplemental Figure 1).

\section{NKA is Impaired After Surgery}

We measured NKA on POD1, 3, 5, 28, and 56 in our CRC patient population (Fig. 2). Astoundingly, 90.2\% (37/41) had IFN $\gamma$ levels below detectable levels $(15.6 \mathrm{pg} / \mathrm{mL})$ on POD1 with the highest value being only $53 \mathrm{pg} / \mathrm{mL}$. The mean reduction in NKA on POD1 compared with baseline was $83.1 \%$ (SD 25.2\%, CI: 75-91), and therefore the study met the primary endpoint of demonstrating a $>75 \%$ decrease in a cohort of CRC surgery patients $(p<0.0001)$. The profound and universal suppression of NKA persisted with $65.5 \%$ (19/ $29)$ and $33.3 \%(4 / 12)$ maintaining levels reduced $>25 \%$ from baseline on POD28 and POD56 respectively.

TABLE 1 Demographic data

\begin{tabular}{lllll}
\hline Category & Subcategory & Healthy donors & Patients & Postop complications \\
\hline Total $(n)$ & & 27 & 42 & $9 / 42$ \\
Blood draws & Baseline $(n)$ & 27 & 42 & - \\
& POD1 $(n)$ & - & 41 & - \\
& POD3 $(n)$ & - & 37 & - \\
& POD5 $(n)$ & - & 12 & - \\
& POD28 $(n)$ & - & 29 & - \\
POD56 $(n)$ & - & 12 & - \\
Gender & Male $(n)$ & 16 & 22 & $7 / 22$ \\
\multirow{4}{*}{ Patient age (median } & Female $(n)$ & 11 & 20 & $2 / 20$ \\
& years; $95 \% C I)$ & $63 ; 58-67$ & $65 ; 60-72$ & - \\
& $<60(n)$ & 10 & 13 & $3 / 13$ \\
Stage & $60-69(n)$ & 13 & 11 & $2 / 11$ \\
& $>70(n)$ & 4 & 18 & $4 / 18$ \\
& I $(n)$ & - & 14 & $3 / 14$ \\
II $(n)$ & - & 11 & $1 / 11$ \\
Type of surgery & III $(n)$ & - & 12 & $5 / 12$ \\
& IV $(n)$ & - & 20 & $0 / 5$ \\
& Open $(n)$ & 22 & $6 / 20$ \\
& Laparoscopic $(n)$ & - & $3 / 22$
\end{tabular}

Italic values indicate the $95 \%$ Confidence Intervals (CI) 


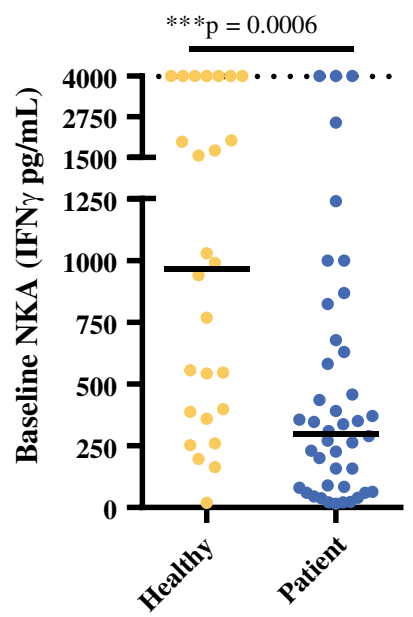

FIG. 1 NK cell IFN $\gamma$ secretion (NKA) is reduced in CRC patients. NKA from healthy donors $(n=27)$ and CRC patients $(n=42)$ before surgery (baseline) was assessed following a $24 \mathrm{~h}$ stimulation with Promoca $^{\mathrm{TM}}$ cytokine cocktail. Upper limit of detection for the NK $\mathrm{Vue}^{\mathrm{TM}}$ assay is $4,000 \mathrm{pg} / \mathrm{mL}$. Median indicated by solid line. MannWhitney $U$ test

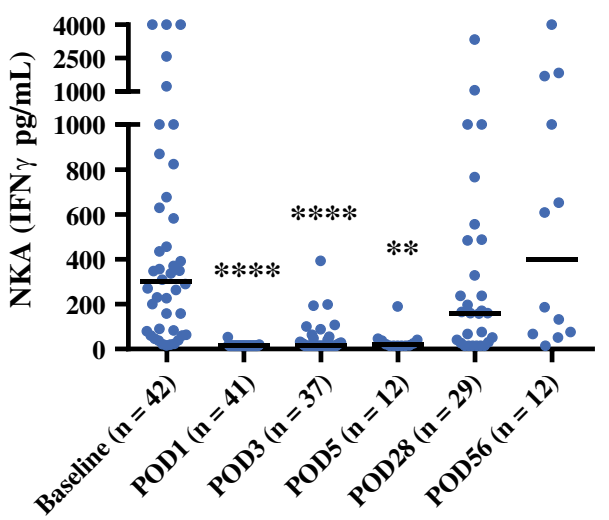

FIG. 2 NK cell IFN $\gamma$ secretion (NKA) is reduced following surgery. NKA measured in CRC surgery patients on the indicated postoperative days (POD). Solid line indicating the median; KruskalWallis tests $(* * p=0.0035$ and $* * * * p<0.0001)$

While no significant difference in NKA based on cancer stage was observed at baseline $(p=0.6$; Supplemental Figure 2a), the impact of the pathological stage was noticeable in postoperative recovery of NKA (Supplemental Figure 2b). On POD28, patients with no systemic or regional metastases (Stage I and II) had a significantly lower median suppression from baseline (36.3\%; CI: - 5.4-70) compared with Stage III and IV patients (85.14\%; CI: $-13.15-93.22 ; p=0.035)$. Examining the impact of open versus laparoscopic surgery on NKA did not reveal any effect of invasiveness of the surgical procedure on the degree of NKA suppression or recovery (Supplemental Figure 3). Lastly, there was a lower baseline and POD28 NKA (although not statistically significant) observed in patients who had a postoperative complication ( $n=9$ complications vs. $n=32$ no complications; Supplemental Figure 4).

\section{NKC is Suppressed to a Lesser Degree Postoperatively}

Next, we compared NKA with NKC, using the ${ }^{51} \mathrm{Cr}$ release assay, in a subset of $\mathrm{HD}(n=12)$ and CRC patients $(n=13)$ at baseline and POD1 (Fig. 3a). The median NKC at an E:T ratio of 100:1 was 30\% (CI: 24.2-32.3) for HD, 41\% (CI: 16.28-43.34) for CRC patients at baseline, and 26\% (CI: 12.2-42.2) on POD1. Similar to our results with NKA, NKC was significantly reduced from baseline following surgical stress $(p=0.0024)$, but the magnitude of suppression was not as profound (24.6\% suppression; range: $50.2-104.3 \%$ )

\section{Impaired NKA is Not Due to Changes in NK Cell Number or Distribution}

We examined the impact of surgery on the absolute number of circulating NK cells by flow cytometry in 23 CRC patients as well as in 15 HD (Fig. 3b; Supplemental Figure 5a). There was a modest but nonsignificant reduction in the number of $\mathrm{NK}$ cells $/ \mathrm{mL}\left(\mathrm{CD}^{-} \mathrm{CD}^{-} 6^{+}\right)$ compared with the HD group (median $0.268 \times 10^{6}$ cells/ $\mathrm{mL}$ to $0.175 \times 10^{6}$ cells $/ \mathrm{mL} ; p=0.2$ ). Furthermore, there was no significant reduction in the number of CD56 ${ }^{\text {bright }}$ or CD56 ${ }^{\mathrm{dim}}$ NK cell subsets after surgery (Table 2). Previous studies of cancer patients observed a significant correlation between the ratio of $\mathrm{CD} 56^{\mathrm{dim}}$-to-CD56 ${ }^{\text {bright }} \mathrm{NK}$ cells and NK function. ${ }^{19,25}$ In the present study, the relative ratio of these populations remained constant following surgery (Supplemental Figure 5b).

Lastly, we detected a significant increase in the number of $\mathrm{CD}_{14}{ }^{+}$monocytes on POD1 (Table 2; Fig. 3c; $p=0.0006)$ and these were predominantly classical and intermediate monocytes (Supplemental Figure 5c), consistent with an immediate release of immature monocytes from the bone marrow during acute injury. ${ }^{26,27}$

\section{DISCUSSION}

In the present study, we demonstrated that NKA is severely suppressed following cancer surgery, with more than $90 \%$ of patients below the limit of detection on POD1 (Fig. 2). The effect was present in every patient, regardless of gender, age, cancer stage or type of surgery. The duration of suppression also was unexpectedly present until POD28 in $65.5 \%$ of patients. The prolonged suppression suggests a degree of immunoparalysis that has implications for the development of postoperative infections and cancer recurrence. 

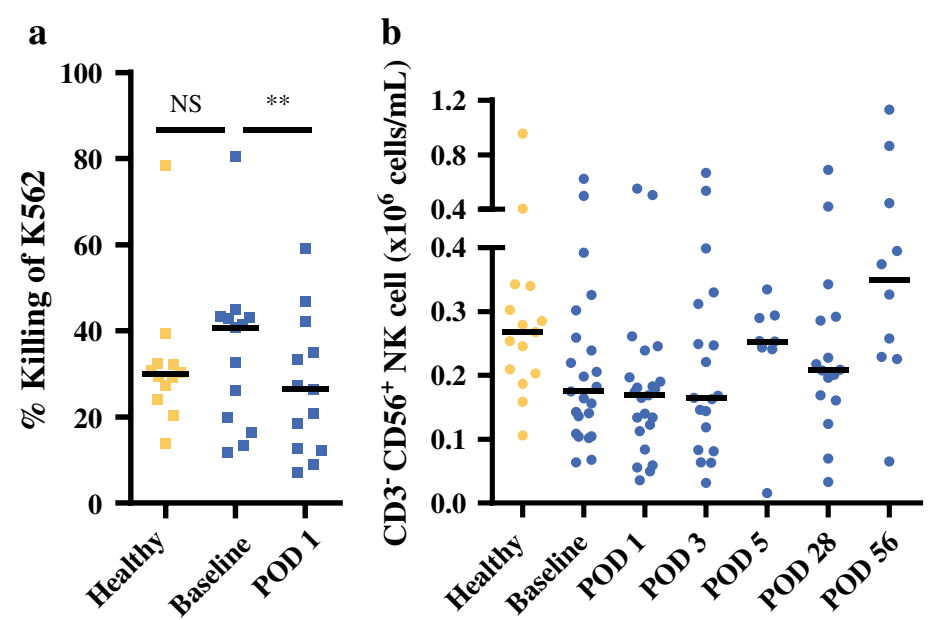

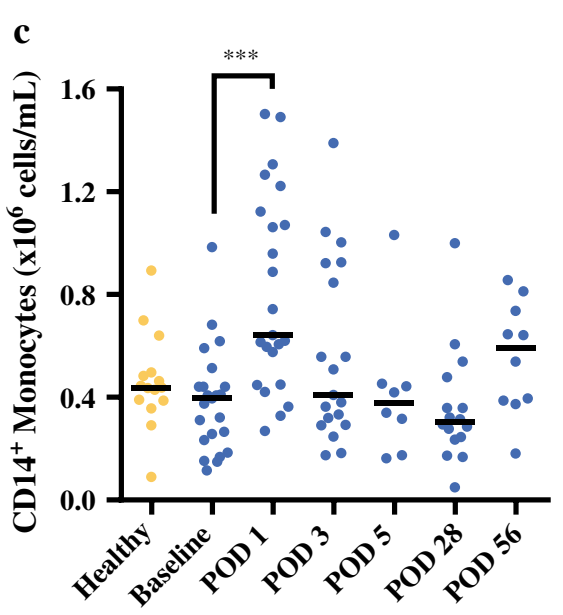

FIG. 3 NK cell cytotoxicity but not cell number is reduced following surgery. a NK cell cytotoxicity in healthy donors $(n=12)$ and CRC patients before and after surgery $(n=13)$. Paired Wilcoxon test (Baseline vs. POD1). Unpaired Mann-Whitney test (Healthy vs.
Baseline). b Circulating NK cells $\left(\mathrm{CD}^{-} \mathrm{CD}^{-} 6^{+}\right)$and (c) monocytes $\left(\mathrm{CD} 14^{+}\right)$in healthy donors $(n=15)$ and CRC surgery patients $(n=16)$ at multiple time points following surgery; Kruskal-Wallis tests

TABLE 2 Median NK cell IFN $\gamma$ secretion, NK cell cytotoxicity, and immune cell profiling data

\begin{tabular}{|c|c|c|c|c|c|c|c|}
\hline Variable & HD & Baseline & POD1 & POD3 & POD5 & POD28 & POD56 \\
\hline NK cell IFN $\gamma$ secretion $(n)$ & 27 & 42 & 41 & 37 & 12 & 29 & 12 \\
\hline IFN $\gamma \mathrm{pg} / \mathrm{mL}$ & 966 & 299.5 & 15.6 & 15.6 & 19.5 & 161 & 398 \\
\hline $95 \% C I$ & $398-2027$ & $159-391$ & $15.6-15.6$ & $15.6-26$ & $13-42$ & $42-329$ & $68-1703$ \\
\hline NK cell cytotoxicity $(n)$ & 12 & 13 & 13 & & & & \\
\hline$\%$ Killing of K562 & 29.95 & 40.76 & 26.44 & & & & \\
\hline \multicolumn{8}{|l|}{ Target Cells } \\
\hline $95 \% C I$ & $24.2-32.3$ & $16.3-43.3$ & $12.2-42.2$ & & & & \\
\hline Immune cell profiling $(n)$ & 15 & 23 & 23 & 19 & 8 & 16 & 10 \\
\hline $\begin{array}{l}\mathrm{CD}^{-} \mathrm{CD}^{-} 6^{+} \mathrm{NK} \text { cell } \\
\left(\times 10^{6} \text { cells } / \mathrm{mL}\right)\end{array}$ & 0.268 & 0.175 & 0.169 & 0.165 & 0.2535 & 0.2085 & 0.3505 \\
\hline $95 \% C I$ & $0.2-0.34$ & $0.14-0.24$ & $0.12-0.19$ & $0.08-0.31$ & $0.02-0.34$ & $0.16-0.29$ & $0.23-0.86$ \\
\hline $\begin{array}{l}\text { CD56 }^{\text {dim }} \text { NK cell } \\
\left(\times 10^{6} \text { cells } / \mathrm{mL}\right)\end{array}$ & 0.249 & 0.144 & 0.131 & 0.145 & 0.213 & 0.1645 & 0.304 \\
\hline $95 \% C I$ & $0.18-0.28$ & $0.10-0.21$ & $0.1-0.17$ & $0.06-0.21$ & $0.01-0.25$ & $0.11-0.27$ & $0.1-0.43$ \\
\hline $\begin{array}{l}\text { CD56 }{ }^{\text {bright }} \mathrm{NK} \text { cell } \\
\left(\times 10^{6} \text { cells } / \mathrm{mL}\right)\end{array}$ & 0.01 & 0.011 & 0.007 & 0.009 & 0.017 & 0.0135 & 0.012 \\
\hline $95 \% C I$ & $0.007-0.015$ & $0.006-0.013$ & $0.004-0.009$ & $0.005-0.015$ & $0.001-0.033$ & $0.004-0.019$ & $0.007-0.023$ \\
\hline $\begin{array}{l}\text { CD14 }{ }^{+} \text {Monocyte } \\
\left(\times 10^{6} \text { cells } / \mathrm{mL}\right)\end{array}$ & 0.438 & 0.396 & 0.643 & 0.41 & 0.3795 & 0.3045 & 0.591 \\
\hline $95 \% C I$ & $0.39-0.5$ & $0.26-0.44$ & $0.58-1.07$ & $0.29-0.92$ & $0.16-1.03$ & $0.24-0.48$ & $0.37-0.81$ \\
\hline
\end{tabular}

Median values, italicized 95\% Confidence Intervals (CI) of the median

Sample size $(n)$ is bolded

The impaired immune response to bacterial pathogens following surgery is well documented, and although the role of NK cells is less clear, studies have shown that IFN $\gamma$ secretion by PBMCs in response to $S$. aureus is reduced following severe injury due to impairment of CD56 $6^{\text {bright }}$
NK cells. ${ }^{28-30}$ Coordinated immune responses against bacterial infection requires the secretion of proinflammatory cytokines (e.g., IL-12, TNF- $\alpha$ ) by innate immune cells to stimulate NK cell IFN $\gamma$ secretion, which promotes an 
effective $\mathrm{T}$ cell response to several pathogens, providing strong evidence for the importance of NK-cell dysfunction in postoperative susceptibility to infections. ${ }^{31-34}$

Impairment of NKA also may have implications for the development of postoperative metastases, although we are not aware of any studies exploring the effect of NKA on cancer outcomes. ${ }^{16} \mathrm{We}$ and others have previously shown that surgical stress results in a significant impairment in $\mathrm{NKC}$, leading to the formation of cancer metastases in animal models. ${ }^{8,24,35-37}$ A clinical study demonstrated that postoperative autologous tumour cell killing is correlated with lung cancer survival. ${ }^{13}$ T-cell dysfunction has been well described following surgical stress, and we have previously published that surgery can render a protective cancer vaccine completely ineffective in a murine model secondary to T-cell suppression. ${ }^{38-40}$ Interestingly, Wirsdorfer et al. demonstrated that surgery-induced impairment of NK-cell IFN $\gamma$ secretion was responsible for T-cell suppression, using OVA-specific T cells. ${ }^{41}$ This provides a provocative hypothesis for the effects of surgery on T-cell mediated antitumour immunity and has implications for perioperative vaccination and immunotherapy strategies.

A second objective of the study was to compare NKA in a cohort of CRC patients to HD of a similar age (Fig. 1). We confirmed that cancer patients have a significant defect in the IFN $\gamma$ secretory capacity as previously reported. 5,19 However, likely due to our small sample size, we did not observe a significant association between cancer stage and NKA at baseline. We did observe a significant reduction in NKA in patients $>70$ years of age, which is consistent with the known effects of aging upon NK-cell function. ${ }^{42,43}$ Because of its reproducibility and simplicity, this assay is currently under development as a screening tool for CRC detection, with preliminary results suggesting similar negative predictive value but higher sensitivity compared with fecal immunochemical tests. ${ }^{23,44}$ NKA was measured from in vitro stimulated samples, which cannot be directly extrapolated to in vivo levels of serum IFN $\gamma$ as recently demonstrated by other groups. ${ }^{16,45}$

When comparing NKA to NKC, we observed three main differences. First, no significant decrease in baseline NKC of CRC patients compared with HD was detected. This is in contrast to other studies and may be explained by the preponderance (25/42 patients, $60 \%$ ) of early-stage patients in our study, which is consistent with findings that NKC is correlated with disease burden in cancer patients. ${ }^{5,19-21,46-48}$ Second, the degree of NKC impairment on POD1 (Fig. 3a) was much less pronounced compared with NKA and was not universally present. This may be a result of using cryopreserved PBMCs to measure NKC, because cryopreservation may have unintended effects on NK-cell function. ${ }^{45}$ Finally, suppression of NKA was still present in the majority of patients at POD28, a time when we have previously reported that NKC is normalized to preoperative levels. ${ }^{8,49}$ One possible explanation is that with $\mathrm{NKC}, \mathrm{NK}$ cells are stimulated with K562 cells, which is known to measure only the activity of $\mathrm{CD}^{\mathrm{dim}}{ }^{\mathrm{dim}}$, whereas with NKA, stimulation is with cytokines, which measures function of both the CD56 bright and $\operatorname{dim}$ NK subsets. ${ }^{50,51}$

To explore this further, we assessed the numbers and subsets of circulating NK cells by flow cytometry. We report that there were no significant changes in the absolute number of $\mathrm{NK}$ cells (Fig. $3 \mathrm{~b}$ ) or ratio of $\mathrm{CD} 56^{\mathrm{dim}}$-toCD56 ${ }^{\text {bright }} \mathrm{NK}$ cells, which confirms that, as expected, NK cells are present but dysfunctional following surgery. Koo et al. reported that NKA was inversely correlated with the $\mathrm{CD} 6^{\text {dim }}$-to-CD56 ${ }^{\text {bright }}$ ratio in prostate cancer patients. ${ }^{5}$ Unfortunately, we were unable to explore such a correlation in the postoperative period, because the NKA was below assay detection in the majority of patients following surgery. Interestingly, there was a significant increase in the number of $\mathrm{CD} 14^{+}$monocytes on POD1 compared with baseline (Fig. 3c). Our group and others have shown that there is a large increase in myeloid-derived suppressor cells (MDSCs) following surgery in humans and in mice. ${ }^{40,52,53}$ We suspect that the large increase in $\mathrm{CD}_{14}{ }^{+}$monocytic cells are likely the expansion of surgery-induced MDSCs; however, we did not assess suppressive function in this study.

NK cells are a main source of IFN $\gamma$ during the initial stages of an innate immune response and are central to the development of an adaptive immune response. ${ }^{54}$ Thus, postoperative suppression of NKA is potentially a major contributor to postoperative cancer recurrence, the early formation of micrometastases, and, more broadly, postoperative infectious complications. We hypothesize that perioperative therapies positioned to prevent or minimize postoperative NK cell dysfunction may improve postoperative cancer outcomes. Currently, we have two ongoing clinical trials of perioperative immunotherapy, which include NKA as a correlative endpoint. ${ }^{15,55}$

ACKNOWLEDGMENT Funding provided by CIHR New Investigator Award, Cancer Research Society, The Ottawa Hospital Academic Medical Organization and in-kind support from ATGen.

DISCLOSURES Study reagents $\left(\mathrm{NK}-\mathrm{Vue}^{\mathrm{TM}}\right)$ provided by ATGen Canada Inc.

OPEN ACCESS This article is distributed under the terms of the Creative Commons Attribution 4.0 International License (http://crea tivecommons.org/licenses/by/4.0/), which permits unrestricted use, distribution, and reproduction in any medium, provided you give appropriate credit to the original author(s) and the source, provide a link to the Creative Commons license, and indicate if changes were made. 


\section{REFERENCES}

1. Lanier LL. NK cell recognition. Аnпu Rev Immunol. 2005;23(1):225-74. https://doi.org/10.1146/annurev.immunol.23. 021704.115526.

2. Ishigami S, Natsugoe S, Tokuda K, et al. Prognostic value of intratumoral natural killer cells in gastric carcinoma. Cancer. 2000;88(3):577-83. https://doi.org/10.1002/(sici)1097-0142(200 00201)88:3\%3c577::aid-cncr13\%3e3.0.co;2-v.

3. Coca S, Perez-Piqueras J, Martinez D, et al. The prognostic significance of intratumoral natural killer cells in patients with colorectal carcinoma. Cancer. 1997;79(12):2320-8. https://doi. org/10.1002/(sici)1097-0142(19970615)79:12\%3c2320::aid-cncr 5\%3e3.0.co;2-p.

4. Imai K, Matsuyama S, Miyake S, Suga K, Nakachi K. Natural cytotoxic activity of peripheral-blood lymphocytes and cancer incidence: an 11-year follow-up study of a general population. Lancet. 2000;356(9244):1795-9. https://doi.org/10.1016/s0140-6 736(00)03231-1.

5. Koo KC, Shim DH, Yang CM, et al. Reduction of the CD16 CD56bright NK cell subset precedes NK cell dysfunction in prostate cancer. PLoS One. 2013;8(11):e78049. https://doi.org/ 10.1371/journal.pone.0078049.

6. Pasero C, Gravis G, Granjeaud S, et al. Highly effective NK cells are associated with good prognosis in patients with metastatic prostate cancer. Oncotarget. 2015;6(16). https://doi.org/10.1863 2/oncotarget. 3965.

7. Joseph J, Seervi M, Sobhan PK, Retnabai ST. High throughput ratio imaging to profile caspase activity: potential application in multiparameter high content apoptosis analysis and drug screening. PLoS One. 2011;6(5):e20114. https://doi.org/10.1371/ journal.pone.0020114.

8. Tai LH, Zhang J, Scott KJ, et al. Perioperative influenza vaccination reduces postoperative metastatic disease by reversing surgery-induced dysfunction in natural killer cells. Clin Cancer Res. 2013;19(18):5104-15. https://doi.org/10.1158/1078-0432.cc $\mathrm{r}-13-0246$

9. Benish M, Bartal I, Goldfarb Y, et al. Perioperative use of $\beta$ blockers and COX-2 inhibitors may improve immune competence and reduce the risk of tumor metastasis. Ann Surg Oncol. 2008;15(7):2042-52. https://doi.org/10.1245/s10434-008-9890-5.

10. Goldfarb Y, Sorski L, Benish M, Levi B, Melamed R, BenEliyahu S. Improving postoperative immune status and resistance to cancer metastasis. Ann Surg. 2011;253(4):798-810. https://doi. org/10.1097/sla.0b013e318211d7b5.

11. Coffey JC, Wang JH, Smith MJF, Bouchier-Hayes D, Cotter TG, Redmond HP. Excisional surgery for cancer cure: therapy at a cost. Lancet Oncol. 2003;4(12):760-8. doi:S1470204503012828.

12. Pollock RE, Lotzová E, Stanford SD. Mechanism of surgical stress impairment of human perioperative natural killer cell cytotoxicity. Arch Surg. 1991;126(3):338. https://doi.org/10.100 1/archsurg.1991.01410270082013.

13. Fujisawa T, Yamaguchi Y. Autologous tumor killing activity as a prognostic factor in primary resected nonsmall cell carcinoma of the lung. Cancer. 1997;79(3):474-81.

14. Klatte T, Ittenson A, Röhl F-W, Ecke M, Allhoff EP, McDougall I. Perioperative immunomodulation with interleukin-2 in patients with renal cell carcinoma: results of a controlled phase II trial. $\mathrm{Br}$ $J$ Cancer. 2006;95(9):1167-73. https://doi.org/10.1038/sj.bjc. 6603391.

15. Auer RC. Trial of perioperative tadalafil and influenza vaccination in cancer patients undergoing major surgical resection of a primary abdominal malignancy (PERIOP-04). https://clinicaltria 1s.gov/ct2/show/NCT02998736.
16. Shaashua L, Shabat-Simon M, Haldar R, et al. Perioperative COX-2 and $\beta$-adrenergic blockade improves metastatic biomarkers in breast cancer patients in a phase-II randomized trial. Clin Cancer Res. 2017;23(16):1-11. https://doi.org/10.1158/ 1078-0432.ccr-17-0152.

17. Cooper MA, Fehniger TA, Turner SC, et al. Human natural killer cells: a unique innate immunoregulatory role for the CD56brightsubset. Blood. 2001;97(10):3146-51. https://doi.org/ 10.1182/blood.v97.10.3146.

18. Michel T, Poli A, Cuapio A, et al. Human CD56 bright NK Cells: An Update. J Immunol. 2016;196(7):2923-31. https://doi.org/10. 4049/jimmunol.1502570.

19. Lee S, Cha J, Kim I, et al. A high-throughput assay of NK cell activity in whole blood and its clinical application. Biochem Biophys Res Commun. 2014;445(3):584-90. https://doi.org/10.1 016/j.bbrc.2014.02.040.

20. Menard C, Blay J-Y, Borg C, et al. Natural killer cell IFN- levels predict long-term survival with imatinib mesylate therapy in gastrointestinal stromal tumor-bearing patients. Cancer Res. 2009;69(8):3563-9. https://doi.org/10.1158/0008-5472.can-083807.

21. Lee J, Park KH, Ryu JH, et al. Natural killer cell activity for IFNgamma production as a supportive diagnostic marker for gastric cancer. Oncotarget. 2017;8(41). https://doi.org/10.18632/oncota rget.19712.

22. Derby EG, Reddy V, Nelson EL, et al. Correlation of human CD56 + cell cytotoxicity and IFN-y production. Cytokine. 2001;13(2):85-90. https://doi.org/10.1006/cyto.2000.0804.

23. Jobin G, Rodriguez-Suarez R, Betito K. Association between natural killer cell activity and colorectal cancer in high-risk subjects undergoing colonoscopy. Gastroenterology. 2017;153(4):980-7. https://doi.org/10.1053/j.gastro.2017.06.009.

24. Tai L-H, de Souza CT, Belanger S, et al. Preventing postoperative metastatic disease by inhibiting surgery-induced dysfunction in natural killer cells. Cancer Res. 2013;73(1):97-107. https://doi. org/10.1158/0008-5472.can-12-1993.

25. Bauernhofer T, Kuss I, Henderson B, Baum AS, Whiteside TL. Preferential apoptosis of CD56dim natural killer cell subset in patients with cancer. Eur J Immunol. 2003;33(1):119-24. http s://doi.org/10.1002/immu.200390014.

26. Jones RO, Brittan M, Anderson NH, et al. Serial characterisation of monocyte and neutrophil function after lung resection. $B M J$ Open Respir Res. 2014;1(1):e000045. https://doi.org/10.1136/b mjresp-2014-000045.

27. Yang J, Zhang L, Yu C, Yang X-F, Wang H. Monocyte and macrophage differentiation: circulation inflammatory monocyte as biomarker for inflammatory diseases. Biomark Res. 2014;2(1):1. https://doi.org/10.1186/2050-7771-2-1.

28. Ertel W, Keel M, Neidhardt R, et al. Inhibition of the defense system stimulating interleukin-12 interferon-gamma pathway during critical illness. Blood. 1997;89(5):1612-20.

29. Yadavalli GK, Chien JW, Wener KM, et al. Interleukin 12 and interferon-gamma synthetic deficiency is associated with dendritic cell cytopenia after cardiac surgery. Shock. 2005;24(1):26-33.

30. Reinhardt R, Pohlmann S, Kleinertz H, Hepner-Schefczyk M, Paul A, Flohé SB. Invasive surgery impairs the regulatory function of human CD56 bright natural killer cells in response to Staphylococcus aureus. suppression of interferon- $\gamma$ synthesis. PLoS One. 2015;10(6):e0130155. https://doi.org/10.1371/journal. pone. 0130155 .

31. Kubica M, Guzik K, Koziel J, et al. A potential new pathway for Staphylococcus aureus dissemination: the silent survival of $\mathrm{s}$. aureus phagocytosed by human monocyte-derived macrophages. PLoS One. 2008;3(1):e1409. https://doi.org/10.1371/journal.pon e.0001409. 
32. Poli A, Michel T, Thérésine M, Andrès E, Hentges F, Zimmer J. CD56 bright natural killer (NK) cells: an important NK cell subset. Immunology. 2009;126(4):458-65. https://doi.org/10.111 1/j.1365-2567.2008.03027.x.

33. Jupelli M, Selby DM, Guentzel MN, et al. The contribution of interleukin-12/interferon- $\gamma$ axis in protection against neonatal pulmonary Chlamydia muridarum challenge. J Interf Cytokine Res. 2010;30(6):407-15. https://doi.org/10.1089/jir.2009.0083.

34. Ramirez-Alejo N, Santos-Argumedo L. Innate defects of the IL$12 / \mathrm{IFN}-\gamma$ axis in susceptibility to infections by mycobacteria and salmonella. J Interf Cytokine Res. 2014;34(5):307-17. https://doi. org/10.1089/jir.2013.0050.

35. Ramirez MF, Ai D, Bauer M, et al. Innate immune function after breast, lung, and colorectal cancer surgery. J Surg Res. 2015;194(1):185-93. https://doi.org/10.1016/j.jss.2014.10.030.

36. Seth R, Tai L-H, Falls T, et al. Surgical stress promotes the development of cancer metastases by a coagulation-dependent mechanism involving natural killer cells in a murine model. Ann Surg. 2013;258(1):158-68. https://doi.org/10.1097/sla.0b013e31 $826 \mathrm{fcbdb}$.

37. Tai LH, Alkayyal AA, Leslie AL, et al. Phosphodiesterase-5 inhibition reduces postoperative metastatic disease by targeting surgery-induced myeloid derived suppressor cell-dependent inhibition of natural killer cell cytotoxicity. Oncoimmunology. 2018;7(6). https://doi.org/10.1080/2162402x.2018.1431082.

38. Delogu G, Moretti S, Antonucci A, et al. Apoptosis and surgical trauma: dysregulated expression of death and survival factors on peripheral lymphocytes. Arch Surg. 2000;135(10):1141-7. http s://doi.org/10.1001/archsurg.135.10.1141.

39. Ishikawa $\mathrm{M}$, Nishioka $\mathrm{M}$, Hanaki $\mathrm{N}$, et al. Perioperative immune responses in cancer patients undergoing digestive surgeries. World J Surg Oncol. 2009;7(1):7. https://doi.org/10.1186/14777819-7-7.

40. Ananth A, Tai L-H, Lansdell C, et al. Surgical stress abrogates Preexisting protective $\mathrm{T}$ cell mediated anti-tumor immunity leading to postoperative cancer recurrence (correction). PLoS One. 2016;11(5):e0155947. https://doi.org/10.1371/journal.pone. 0155947.

41. Wirsdörfer F, Bangen JM, Pastille E, Hansen W, Flohé SB. Breaking the co-operation between bystander T-cells and natural killer cells prevents the development of immunosuppression after traumatic skeletal muscle injury in mice. Clin Sci. 2015;128(11):825-38. https://doi.org/10.1042/cs20140835.

42. Solana R, Alonso MC, Peña J. Natural killer cells in healthy aging. Exp Gerontol. 1999;34(3):435-43. https://doi.org/10.1016/ s0531-5565(99)00008-x.

43. Lee DH, Kim M, Kim M, et al. Age-dependent alterations in serum cytokines, peripheral blood mononuclear cell cytokine production, natural killer cell activity, and prostaglandin F2 $\alpha$. Immunol Res. 2017;65(5):1009-16. https://doi.org/10.1007/s120 26-017-8940-0.

44. Levy BT, Bay C, Xu Y, et al. Test characteristics of faecal immunochemical tests (FIT) compared with optical colonoscopy.
J Med Screen. 2014;21(3):133-43. https://doi.org/10.1177/ 0969141314541109.

45. Gotlieb N, Rosenne E, Matzner P, Shaashua L, Sorski L, BenEliyahu $\mathrm{S}$. The misleading nature of in vitro and ex vivo findings in studying the impact of stress hormones on NK cell cytotoxicity. Brain Behav Immun. 2015;45:277-86. https://doi.org/10. 1016/j.bbi.2014.12.020.

46. Bücklein V, Adunka T, Mendler AN, et al. Progressive natural killer cell dysfunction associated with alterations in subset proportions and receptor expression in soft-tissue sarcoma patients. Oncoimmunology. 2016;5(7):e1178421. https://doi.org/10.1080/ 2162402x.2016.1178421.

47. MacFarlane AW, Jillab M, Smith MR, et al. NK cell dysfunction in chronic lymphocytic leukemia is associated with loss of the mature cells expressing inhibitory killer cell Ig-like receptors. Oncoimmunology. 2017:e1330235. https://doi.org/10.1080/2162 402x.2017.1330235.

48. Konjević G, Jurišić V, Spužić I. Association of NK cell dysfunction with changes in LDH characteristics of peripheral blood lymphocytes (PBL) in breast cancer patients. Breast Cancer Res Treat. 2001;66(3):255-63. https://doi.org/10.1023/a: 1010602822483

49. Velásquez JF, Ramírez MF, Ai DI, Lewis V, Cata JP. Impaired immune function in patients undergoing surgery for bone cancer. Anticancer Res. 2015;35(10):5461-6. http://www.ncbi.nlm.nih.g ov/pubmed/26408709.

50. Anfossi N, André P, Guia S, et al. Human NK cell education by inhibitory receptors for MHC class I. Immunity. 2006;25(2):331-42. https://doi.org/10.1016/j.immuni.2006.06. 013.

51. De Maria A, Bozzano F, Cantoni C, Moretta L. Revisiting human natural killer cell subset function revealed cytolytic CD56dimCD16 + NK cells as rapid producers of abundant IFNon activation. Proc Natl Acad Sci. 2011;108(2):728-32. https://d oi.org/10.1073/pnas.1012356108.

52. Wang J, Yang L, Yu L, et al. Surgery-induced monocytic myeloid-derived suppressor cells expand regulatory $\mathrm{T}$ cells in lung cancer. Oncotarget. 2017;8(10):17050-8. https://doi.org/10.1863 2/oncotarget.14991.

53. Wang J, Su X, Yang L, et al. The influence of myeloid-derived suppressor cells on angiogenesis and tumor growth after cancer surgery. Int J Cancer. 2016;138(11):2688-99. https://doi.org/10. 1002/ijc.29998.

54. Thäle C, Kiderlen AF. Sources of interferon-gamma (IFN- $\gamma$ ) in early immune response to Listeria monocytogenes. Immunobiology. 2005;210(9):673-83. https://doi.org/10.1016/j.imbio.2005. 07.003.

55. Auer RC. Perioperative immunonutrition in colorectal cancer patients undergoing abdominal surgery (PERIOP-02). https://cli nicaltrials.gov/ct2/show/NCT02987296. 